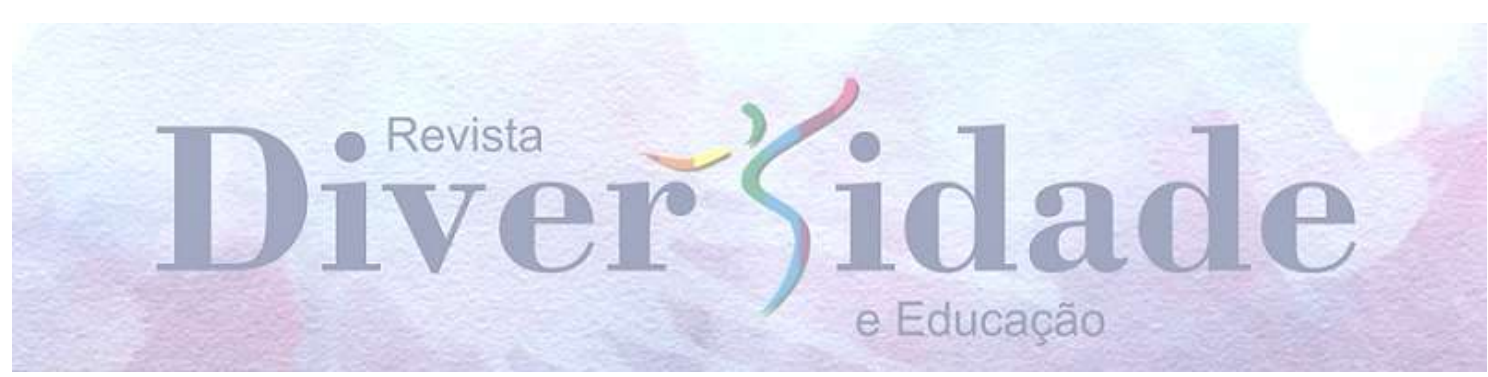

\title{
DONAS DO PLACAR: UMA EXPERIÊNCIA DE RADIOJORNALISMO ESPORTIVO COM O PROTAGONISMO DAS MULHERES
}

\author{
DONAS DO PLACAR: UNA EXPERIENCIA DE RADIOJORNALISMO \\ DEPORTIVO CON EL PROTAGONISMO DE LAS MUJERES
}

\author{
DONAS DO PLACAR: AN EXPERIENCE OF SPORTS \\ RADIOJORNALISM WITH PROTAGONISM OF WOMEN
}

\author{
Fernanda Nascimento ${ }^{1}$ \\ Leslie Sedrez Chaves ${ }^{2}$
}

\section{RESUMO}

O protagonismo das mulheres no jornalismo esportivo é um desafio cultural e social. Nas coberturas esportivas, a visibilidade de homens é hegemônica entre atletas e profissionais da imprensa, sendo raras as exceções. No presente artigo, apresentamos os primeiros resultados do Donas do Placar, projeto de extensão que formou uma equipe de radiojornalismo composta exclusivamente por mulheres e realizou a transmissão experimental de jogos da Copa do Mundo de Futebol Feminino de 2019. As discentes que participaram do projeto desenvolvido no departamento de Jornalismo da Universidade Federal de Santa Catarina, produziram conteúdos multimídia e seu trabalho foi reconhecido pela comunidade local e pela imprensa regional.

PALAVRAS-CHAVE: Jornalismo. Gênero. Radiojornalismo esportivo. Educação.

\section{RESUMEN}

El protagonismo de las mujeres en el periodismo deportivo es un desafío cultural y social. En las coberturas deportivas, la visibilidad de los hombres es hegemónica entre los atletas y los profesionales de los medios, con raras excepciones. En este artículo, presentamos los primeros resultados de Donas do Placar, un proyecto de extensión que formó un equipo de radioperiodismo formado exclusivamente por mujeres y llevó a cabo la transmisión experimental de juegos para la Copa Mundial de Fútbol Femenino de 2019. Las estudiantes que participaron en el proyecto desarrollado en el

\footnotetext{
${ }^{1}$ Doutora em Ciências Humanas.

2 Doutora em Comunicação Social. Universidade Federal de Santa Catarina, Florianópolis, Santa Catarina, Brasil.
} 
departamento de Periodismo de la Universidade Federal de Santa Catarina, produjeron contenido multimedia y su trabajo fue reconocido por la comunidad local e por los medias regionales.

PALABRAS-CLAVE: Periodismo. Género. Radioperiodismo deportivo Educacion.

\section{ABSTRACT}

The leading role of women in sports journalism is a cultural and social challenge. On sports coverage, the visibility of men is hegemonic between athletes and media professionals, with rare exceptions. In this article, the initial results of Donas do Placas, an extension project that built a team of radio journalists composed exclusively by women and carried out the experimental transmission of the 2019 Women's World Cup games, are presented. The students who participated of the project developed in the department of Jornalism of Universidade Federal de Santa Catarina produced multimedia content, and this production was recognized by the local community and regional media.

KEYWORDS: Jornalism. Genre. Radio Journalism. Education.

$$
* * *
$$

\section{Introdução}

A reivindicação pela presença das mulheres no jornalismo esportivo tem crescido nos últimos anos. Apesar da presença na cobertura dos esportes ter se iniciado em 1947, com o ingresso da repórter Maria Helena Rangel no jornal Gazeta Esportiva, a participação de mulheres nesta área é marcada pela limitação dos espaços de atuação.

Em uma sociedade na qual não apenas as pessoas, como as instituições são generificadas (SCOTT, 1995), o espaço do jornalismo esportivo se construiu como um reduto no qual a masculinidade é exacerbada. Uma mirada de gênero contribui para compreender as disparidades e desafios do campo e os motivos pelos quais a presença segmentada/autorizada de poucos corpos é naturalizada no espaço. Nas disputas envolvendo o conceito (HARAWAY, 2004), compreende-se aqui que gênero é "um modo primeiro de significar as relações de poder" (SCOTT, 1995, p. 86), marcadamente histórico e contextual, um campo em permanente disputa.

Ao analisarmos as relações de poder que construíram o jornalismo esportivo, destaca-se a articulação de dois campos nos quais a presença de corpos de homens (cisgêneros, com masculinidades hegemônicas) garantem posições e poder e destaque: jornalismo e esporte. O jornalismo é entendido aqui como uma das esferas de construção social da realidade (BERGMAN; LUCKMANN, 2004) e, como produtor de 
sentidos, é uma das maneiras pelas quais se produzem percepções sobre a realidade, extremamente relacionados ao senso comum (MEDITSCH, 2002).

De maneira geral, o campo do Jornalismo é, como afirma Márcia Veiga da Silva (2014), "masculino". Valores como poder e hierarquia se fazem presentes desde o ensino (VEIGA DA SILVA, 2014) até as rotinas de produção (VEIGA DA SILVA, 2015), com consequências nas produções disseminadas e compartilhadas socialmente. O campo é uma dos responsáveis pelo "acervo comum de conhecimentos" (MEDITSCH, 1997) de que o esporte é um campo masculino. O complexo sistema se perpetua por questões estruturais e subjetividades. Como afirma Veiga da Silva, em etnografia em uma redação jornalística:

\begin{abstract}
Analisando os valores e as concepções de gênero dos jornalistas, o estudo interpretou uma relação direta entre o perfil dos profissionais e o tipo de notícia que o mesmo iria produzir, e que nesta relação intrínseca gênero também era um elemento pervasivo e determinante. Esta percepção se deu não apenas por serem os profissionais sujeitos constituídos de gênero, mas também por serem as notícias igualmente hierarquizadas numa escala de valores, a partir de suas características, que igualmente estavam relacionadas aos atributos convencionais de gênero (fortes/leves; sérias/lúdicas; risco/cuidado etc). Assim, entre as pautas, como entre os repórteres, havia uma hierarquia de valores correspondentes, e as concepções de gênero estavam presentes na idealização das matérias, bem como permeavam as escolhas dos jornalistas que iriam realizá-las (VEIGA DA SILVA, 2015, p. 321).
\end{abstract}

Evidentemente essa não é uma construção desenvolvida apenas pelo Jornalismo. A percepção social do campo esportivo como um espaço masculino é atravessada por contribuições e regulações de diversas áreas do conhecimento. Ainda que tenham ocorrido alterações nos últimos anos, é necessário resgatar que as sistemáticas discriminações sofridas pelas mulheres durante décadas impediu o desenvolvimento esportivo de muitas atletas. No Brasil, entre 1941 e 1979, as mulheres foram proibidas por lei de praticar determinadas modalidades, entre elas o futebol - prática esportiva objeto da cobertura desenvolvida pelas alunas que participaram do projeto de extensão. Como afirma Silvana Goellner (2005), até as últimas décadas do século XX, a participação de mulheres em eventos esportivos era um "temor" para as famílias brasileiras. A perda de atributos da feminilidade, a exibição do corpo, a aquisição de força muscular eram considerados "anti-naturais" para as mulheres - especialmente as 
brancas, já que a socialização de mulheres negras é assentada em outra sociabilidade, na qual a força física se faz presente (DAVIS, 2016).

As interdições sofridas não significaram a ausência completa de mulheres no jornalismo esportivo ou desenvolvendo atividades desportivas, mas contribuiu para que a nossa presença, tomando de empréstimo uma expressão de Stuart Hall, fosse marcada por uma "visibilidade cuidadosamente regulada e segregada" (2013, p. 377).

O panorama do século XXI demonstra que mesmo décadas depois do ingresso das mulheres nos segmentos, seguimos ocupando poucos espaços neste segmento. A presença de mulheres no jornalismo esportivo, em 2017, era de 11,4\% no Brasil (BUENO, 2018). De acordo com levantamento realizado pela Gênero e Número (2016), apenas $10 \%$ das colunas esportivas dos dez jornais com maior circulação nos estados brasileiros são assinadas por mulheres. Nos programas esportivos de TV por assinatura, apenas $13 \%$ das profissionais são mulheres - praticamente todas ocupando a função de reportagem, deixando comentários e apresentação majoritariamente para homens. Conforme Noemi Correa Bueno, em estudo sobre os programas esportivos de Brasil e Portugal é possível identificar que

[...] ainda existe uma cultura androcêntrica presente em programas de esportes na televisão aberta brasileira e portuguesa, apresentando possibilidades diferentes de atuações para jornalistas homens e mulheres, veiculando e contribuindo para a manutenção de representações sobre o que é ser feminino e masculino a partir de referências androcêntricas, binárias e heteronormativas $(2018$, p. 11).

Relatos de situações de abuso, intimidação, assédio e discriminação são comuns entre as mulheres que figuram como exceção no espaço. Em 2018, 52 profissionais que atuam em diferentes veículos do país, iniciaram o movimento \#DeixaElaTrabalhar, estimulando um debate sobre atitudes de colegas e torcedores que inibem a presença das mulheres neste segmento.

O surgimento do projeto Donas do Placar está diretamente associado a este cenário e ao descontentamento de discentes e docentes com a presença restrita das alunas nas coberturas esportivas realizadas pelo curso. A insatisfação foi mobilizadora para a criação da equipe, cuja trajetória será apresentada na próxima seção.

As reflexões apresentadas por nós, docentes que coordenamos o projeto, partem de princípios teóricos e procuram estender uma transformação para a prática profissional. Afinal, como afirma Michel Foucault, a “[...] a teoria não expressará, não 
traduzirá, não aplicará uma prática; ela é uma prática" (FOUCAULT, 2012, p. 132). O discurso integra a prática e é a partir da capacidade reflexiva que somos capazes de produzir o conhecimento inerente a atuação enquanto jornalistas.

\section{"E se fizéssemos a cobertura da Copa do Mundo de Futebol Feminino?": as articulações do projeto}

O ano era 2018 e a Copa do Mundo de Futebol Masculino movimentava todo o planeta. Nas telas, rádios e impressos, futebol praticado por homens em uma das maiores competições esportivas mundiais mobilizava a todos. Nos corredores do departamento de Jornalismo da UFSC não poderia ser diferente. Os alunos se mobilizaram e especialmente a partir da equipe de radiojornalismo esportivo da rádio web Rádio Ponto.

A equipe, que já contava com um programa esportivo semanal na grade de programação da rádio e esporadicamente cobria jogos de futebol, como os da Champions League (transmitidos em horários nos quais o departamento estava em funcionamento e os recursos disponíveis para os alunos, ao contrário das transmissões do futebol brasileiro), percebeu a oportunidade de aperfeiçoar fundamentos necessários para as jornadas esportivas. Organizados, convocaram outros discentes para participar do projeto e desenvolveram as seguintes ações: cobertura de todos os jogos possíveis do evento; criação de programa semanal sobre a Copa do Mundo, com informações e mesa redonda, transmitido na Rádio Ponto e no TJ UFSC; criação de drops veiculados antes do evento, com informações sobre as seleções participantes, características culturais de cada país e dados sobre as cidades sede; além de programas especiais antes e depois da Copa do Mundo.

Não havia requisitos para participar da cobertura, bastava tempo e disposição para aprender. Mas, por um motivo não explícito, poucas mulheres toparam o desafio. Nenhuma partida foi narrada por elas e o evento com maior visibilidade que participaram foi uma mesa redonda, com participação exclusiva de quatro alunas. Discentes que não participaram do evento demonstraram descontentamento e evidenciaram aspectos que as afastavam dos microfones da rádio: episódios anteriores de machismo que envolviam situações de constrangimento. Os relatos fizeram com que não apenas pudéssemos refletir sobre o problema, mas apresentar uma possibilidade de inclusão das mulheres em coberturas esportivas de grande porte: "e se fizéssemos a 
cobertura a Copa do Mundo de Futebol Feminino?” foi a pergunta lançada como desafio às alunas. Como afirma Ana Célia da Silva, "o professor pode vir a ser um mediador inconsciente dos estereótipos se for formado com uma visão acrítica das instituições e por uma ciência tecnicista e positivista, que não contempla outras formas de ação e reflexão" (2005, p. 24). Nosso desafio era propor outras experiências.

O ensino é de suma importância e muitas vezes, como aponta Márcia Veiga da Silva, a atividade de docência é "relegada a um lugar secundário na hierarquia da Universidade", o que, na formação dos futuros jornalistas pode significar uma prática profissional nas quais "se refletem uma hierarquia excludente que incide diretamente nas dificuldades dos encontros com a alteridade e do diálogo com a diferença, parte fundamental e presente nos processos de conhecer" (VEIGA DA SILVA, 2015, p. 265). Neste sentido, também cabe ao docente investir em práticas pedagógicas capazes de promover rupturas, ampliando e aprofundando a relação com os discentes e potencializando os processos de aprendizado.

Importante salientar que o projeto de extensão também buscava cumprir com os objetivos da própria universidade, na medida em que a garantia da pluralidade de corpos e vozes e de uma equidade nas condições de aprendizado é um dos desafios da instituição. Conforme o Plano de Desenvolvimento Institucional da UFSC, a extensão exerce "um papel fundamental na integração entre universidade e sociedade" sendo fundamental para que a instituição se "mantenha apta a responder às necessidades externas por meio do conhecimento adquirido com as interações proporcionadas por essas ações" (UFSC, 2020, p. 22).

\section{“Alguém precisa narrar”: os desafios do projeto}

A presença de 30 alunas motivadas a realizar a cobertura demonstrou que a participação restrita de mulheres na cobertura da Copa do Mundo de Futebol Masculino de 2018 não estava relacionada ao desinteresse das alunas, mas a uma cultura partilhada que sistematicamente as exclui do jornalismo esportivo.

Calouras e veteranas, envolvidas ou não com o esporte, as alunas demonstraram satisfação em serem convidadas para participar de uma cobertura esportiva, algo incomum. Nos dois primeiros encontros a existência de um grupo exclusivo foi questionada por algumas das alunas - que haviam participado da cobertura anterior causou discussão. A exposição dos desconfortos pelas colegas contribuiu para que todas 
pudessem perceber o problema enfrentado, não apenas no curso. E também foi importante para que mesmo aquelas que conseguiam integrar estes espaços pudessem perceber quais posições ocupavam, em quais momentos suas vozes eram escutadas e as maneiras sutis de segregação que ocorriam nos estúdios.

Discutir sobre a possibilidade de errar foi um dos primeiros desafios do projeto. O medo em fracassar e expor aos demais o próprio processo de aprendizado aterrorizava algumas das estudantes. Com a inexperiência da maioria das alunas em coberturas deste porte, definimos a realização de uma jornada mais enxuta: criação de podcast de cada seleção e cobertura ao vivo de 10 jogos (com prioridade para os jogos da seleção brasileira); em um segundo momento, dependendo da capacidade da equipe, realização de programas semanais na Rádio Ponto e participação no telejornal TJ UFSC.

O principal desafio surgiria ainda na primeira reunião: quem iria narrar? Ainda que a primeira narração de jogo de futebol realizada por uma mulher tenha ocorrido em 1972 - quando Zuleide Ranieri narrou Brasil X Checoslováquia - essa é uma função na qual a presença de mulheres é muito rara e motivo de notícia quando acontece. Relevante destacar que a ausência de mulheres na função está relacionada às sistemáticas desautorização da presença de mulheres, consideradas inadequadas para a narração por serem "emotivas", o que teria como consequências "gritos" na transmissão (JHALLY, 2016). Como afirma Bueno:

\begin{abstract}
No jornalismo esportivo, a entrada na mulher seguiu a tendência da entrada da mulher no mercado de trabalho como um todo: eram grandes as barreiras impostas para as mulheres ingressarem na vida profissional, como a hostilidade presente na própria família até as intimidações físicas, insinuações de desqualificação, menores salários e assédios sexuais. Na contemporaneidade, apesar de algumas dessas barreiras terem sido superadas, mulheres ainda apresentam várias dessas dificuldades para inserirem no campo do jornalismo esportivo (2018, p. 26-27).
\end{abstract}

Nenhuma das integrantes da equipe havia desempenhado a função, considerada a mais importante em uma transmissão esportiva. Para narrar é necessário saber não apenas apresentar os acontecimentos do jogo, mas também ter a capacidade de interação com repórteres, comentaristas e plantonistas, além do diálogo com o público, que participa a partir de redes sociais. A função também é perpassada pelo conhecimento das regras do esporte, pelo desprendimento e pela emotividade (ainda que a mesma seja criticada em mulheres). 
Em decorrência da inexperiência da maioria das integrantes em coberturas esportivas, foi definida a realização de duas oficinas, nas quais as noções básicas de narração, reportagem e comentários em partidas de futebol foram apresentados. Outra estratégia foi o treinamento a partir da cobertura de um amistoso e um jogo gravado, sem transmissões externas.

Ao longo do projeto, contamos com apenas três alunas exercendo essa função - o que impediu a transmissão de outros jogos, inclusive. $\mathrm{O}$ revezamento foi mais amplo entre repórteres, comentaristas e plantonistas. A Copa do Mundo de Futebol Feminino possui menos equipes do que o evento protagonizado por homens $(24$, ao invés de 32 seleções) e uma cobertura mais restrita. Desigualdade de recursos e de visibilidade são lembrados como obstáculos ao desenvolvimento de atletas e torcedores envolvidos com o evento. Na premiação oferecida pela Federação Internacional de Futebol (Fifa) para as seleções participantes dos torneios, a discrepância torna-se evidente: o futebol praticado por homens recebe US\$ 400 milhões distribuídos conforme a colocação; entre as mulheres a divisão é de US\$ 30 milhões. As desigualdades entre os eventos e coberturas demonstrou ser um desafio adicional para nosso projeto. A ausência de informações sobre as seleções, mesmo nos sites nativos dos países participantes, tornou a produção dos drops sobre as seleções um desafio. Com poucas informações sobre os times, muitas alunas precisaram incluir informações culturais das nações e outros detalhes não previstos. A falta de informações também teve impacto nas próprias transmissões, diminuindo o repertório das alunas.

Os meses de abril e maio, que antecederam o evento esportivo, foram utilizados para o planejamento da jornada e a produção dos 24 drops, disponibilizados na plataforma Spotify. Neste período também foram realizadas as oficinas e a cobertura dos amistosos, a criação de vinhetas e a definição da identidade visual do grupo - também criada por alunas do curso. 
FIGURA 1: Identidade Visual

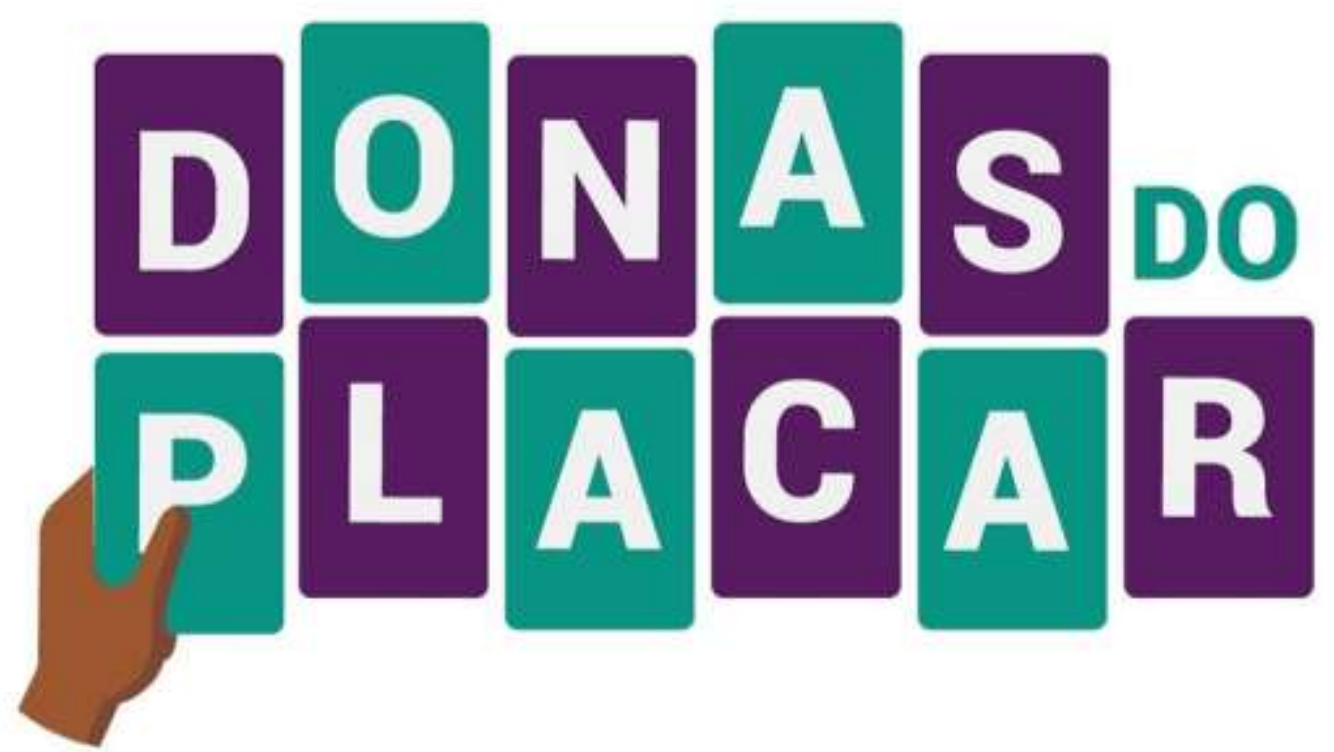

Autoras: Júlia Mallmann e Daniela Müller

O jogo de abertura da Copa, em 7 de junho, marcou a estreia ao vivo da equipe. Entre junho e julho, a equipe realizou a cobertura dos jogos: Holanda X Suécia (3/7); Inglaterra X Estados Unidos (2/7); Holanda X Japão (25/6); Itália X Brasil (18/6); Brasil X Austrália (13/6); Chile X Suécia (11/6); França X Coreia do Sul (7/6).

Nas transmissões, pelo menos cinco integrantes se desdobravam nas funções de narração, reportagem (duas pessoas), plantão e comentário. Das redes sociais vinham interações e perguntas, enviadas pelas plataformas do Instagram, Facebook e Twitter, nos quais outras integrantes respondiam. Ao vivo e na internet, a equipe procurava apresentar informações de qualidade, sem abandonar a descontração do entretenimento futebolístico.

O nervosismo foi uma constante, amenizado com o passar dos minutos em cada transmissão e com a experiência que as jornadas iam trazendo. Os erros, levados para a cobertura pós-jogo em forma de troça, com o quadro "frase da jornada", ajudavam a diminuir a tensão e a sensação de fracasso.

Ao longo das transmissões fomos percebendo, enquanto coordenadoras, uma ampliação da segurança das integrantes e a criação de elos horizontais de cooperação, nas quais a troca de informações e apoio era determinante para o resultado do processo de desenvolvimento. 
O estímulo à utilização das distintas habilidades das alunas ao longo do projeto proporcionou o desenvolvimento de conteúdos audiovisuais, não previstos, que também foram disponibilizaram nas redes sociais. Assim como a realização de comentários e minuto a minuto no Twitter.

Evidentemente que as dificuldades também foram significativas. $O$ fato do projeto não estar vinculado a nenhuma disciplina do curso fez com que a mobilização dependesse exclusivamente da motivação e responsabilidade de cada estudante - o que nem sempre foi perceptível. A sobrecarga de trabalho nossa e de algumas estudantes causou desgastes. Também é necessário salientar que a data do evento, coincidindo com o período de encerramento do semestre letivo, contribuiu para que em muitos momentos as equipes fossem concluídas horas antes do jogo - diminuindo a qualidade da transmissão, pelo menor tempo disponível para o estudo de cada equipe.

As restrições técnicas enfrentadas na universidade e mesmo fora dela tornaram o trabalho mais complicado. Emissoras esportivas de televisão a cabo anunciaram a transmissão de todos os jogos, mas alteraram suas grades. E, por coincidência, um destes jogos, entre Chile X Suécia, teve a transmissão anunciada pelo projeto, mas não foi veiculado nos canais brasileiros. A solução, encontrada menos de cinco minutos antes do início da partida, foi acompanhar via internet um canal de televisão chilena. $\mathrm{O}$ fato inusitado nos leva a acreditar que Chile X Suécia foi transmitido em apenas um local no Brasil: pela equipe do Donas do Placar.

Os números de acesso das redes sociais do projeto demonstram o sucesso da iniciativa. No Twitter, 793 seguidores; no Facebook, 682 seguidores; no Instagram, 980. Ao longo das transmissões, alguns jogos tiveram o acompanhamento em 1200 computadores e celulares, simultaneamente. 
FIGURA 2: Transmissões

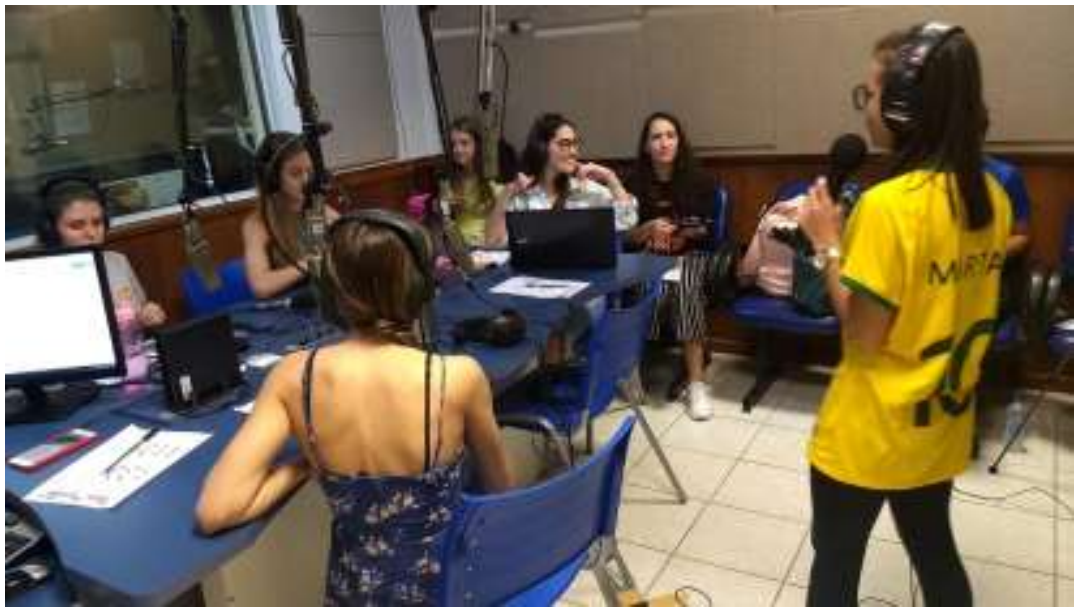

Fonte: Leslie Chavez

\section{“Elas são as Donas do Placar": o projeto sai da universidade}

A repercussão do projeto foi imediata. Com o envio de releses divulgando a proposta, a repercussão nacional das transmissões realizadas em televisão aberta por grandes grupos de comunicação, aliada ao fato das alunas integrarem um curso de Jornalismo e possuírem contatos em veículos de comunicação, o projeto começou a receber pedidos de entrevista da imprensa do Estado.

O projeto foi noticiado nos portais Dibradoras e Catarinas, rádios $\mathrm{CBN}$ e Guarujá; na Band TV; nos jornais A Hora de Santa Catarina e Diário Catarinense, além de ser replicado em outros sites de internet. Além da mídia, estudantes de outras universidades entraram em contato solicitando informações, com a intenção de desenvolver atividades semelhantes em suas instituições de ensino.

Ao longo da Copa do Mundo, as alunas foram convidadas em diversas oportunidades a participarem do podcast especial produzido pelo Mamilos e suas análises ou reportagens sobre as partidas atingiram públicos em todo o Brasil. 
FIGURA 3: Reportagem sobre o projeto nos jornais A Hora e Diário Catarinense
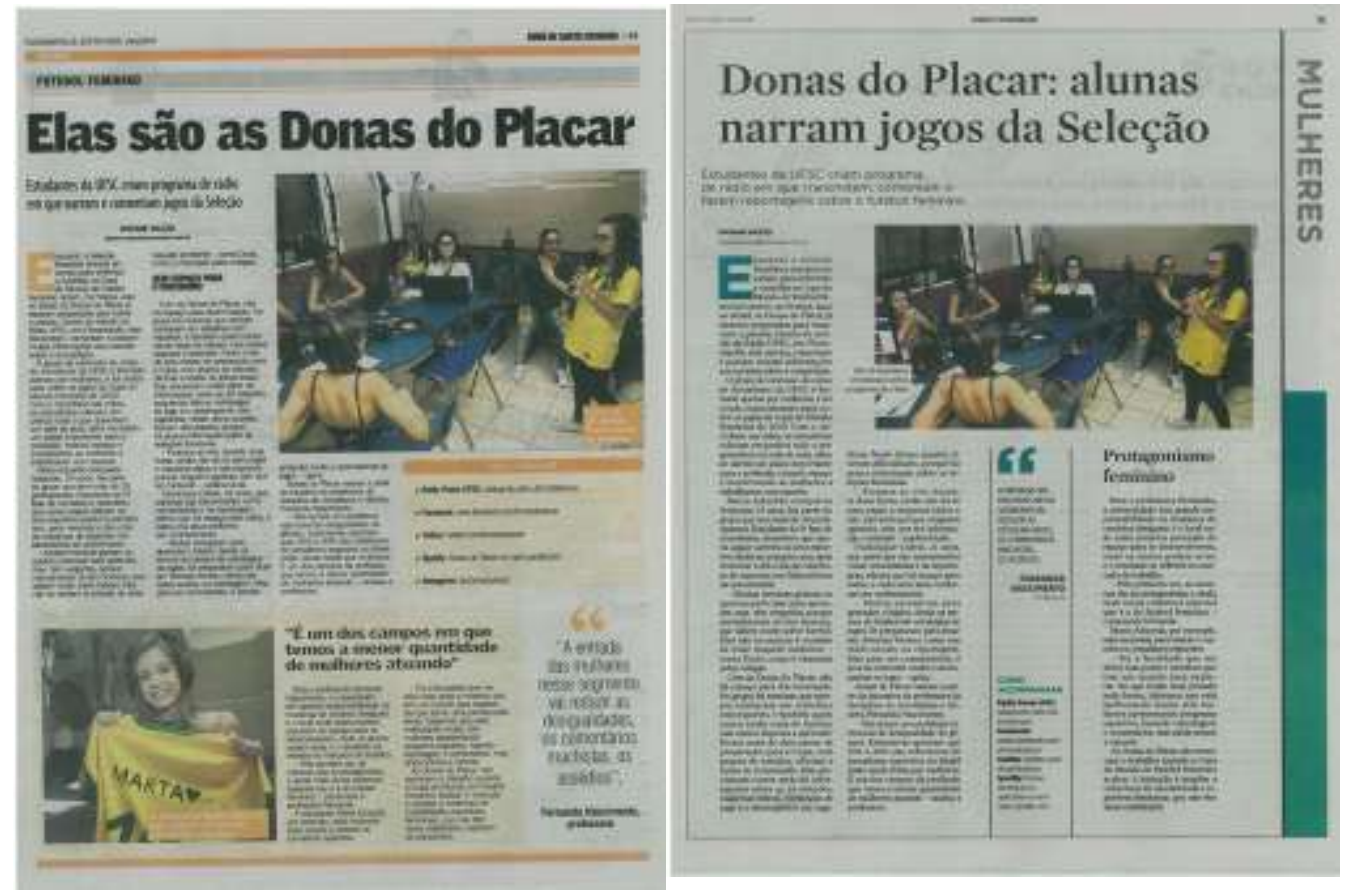

Fonte: A Hora e Diário Catarinense (14/6/2019)

A repercussão se estendeu para além da Copa. Com o encerramento da proposta, algumas das integrantes do projeto começaram a ser convidadas para participar de programas esportivos (na rádio CBN) e a realizar a cobertura da Copa Floripa Brasil, um evento que reuniu categorias de futebol amador em Florianópolis. Em março de 2019, meses depois da conclusão da primeira etapa do projeto, parte da equipe foi convidada pela rádio Avaí - rádio oficial do clube de Florianópolis - para cobrir um jogo da equipe de homens, pelo campeonato catarinense. O jogo entre Avaí X Juventus, em 8 de março, teve como narradora Duda Dalponte, na reportagem Thaisy Regina e Sime Malagoli (repórter da rádio Avaí) e nos comentários Maria Heloisa Vieira. A narração do gol da virada do Avaí, nos acréscimos do jogo, foi filmada e postada no Twitter e repercutiu pelo país. Mais de 8 mil curtidas na rede social e transmissão em programas esportivos da Sportv, com comentários de jornalistas consagrados no setor esportivo como Ana Thaís e Gustavo Villani, incentivando a discente a seguir com a carreira. Em sua maioria, os comentários estimulavam as alunas a seguirem o caminho do jornalismo esportivo. 


\section{Donas e além: considerações preliminares}

A trajetória inicial do projeto de extensão Donas do Placar demonstra o sucesso da iniciativa e sua importância na universidade. Ao oportunizar um espaço de aprendizado para alunas, o projeto contribuiu para a redução de desigualdades, a descoberta de novos talentos e a criação de laços entre as discentes, que descobriram com erros e acertos novas possibilidades de atuação no jornalismo.

A produção multimídia de drops, conteúdos audiovisuais e sonoros e as transmissões ao vivo oportunizam um amplo leque de aprendizados práticos, nas quais a reflexão sobre desigualdades estava sempre presente e o compromisso com a construção de uma educação e um jornalismo menos desigual também.

A proposta de fomentar o protagonismo de mulheres gerou um grande engajamento e encorajou alunas. E, certamente, teve repercussão também entre os alunos, que perceberam que suas práticas eram excludentes e podem agora pensar na atuação conjunta, tendo em vista o reconhecido talento das alunas.

A segurança adquirida com a experiência de produção de conteúdo se transformou em oportunidades para além dos muros da universidade e esperamos que resulte na inclusão de mais jornalistas no campo desportivo.

$\mathrm{O}$ projeto explicitou a necessidade do engajamento articulado de docentes e discentes e a necessidade de escuta atenta para as demandas. Além de criticar e denunciar situações de sistemáticas exclusões, cabe aos profissionais de ensino, junto aos alunos, refletir e produzir rupturas no processo educativo, trabalhando para produzir novas oportunidades.

Por fim, é preciso destacar que iniciativas como o Donas do Placar são também uma responsabilidade das instituições de ensino, que devem garantir a pluralidade e ambientes seguros de aprendizado, respeitando as diferenças e identificando desigualdades que precisam ser superadas.

\section{Referências}

BERGMAN, Peter; LUCKMANN, Thomas. A construção social da realidade. Petrópolis: Vozes, 2004.

BUENO, Noemi Corrêa. A invisibilidade das mulheres em programas esportivos de TV: estudo de casos no Brasil e em Portugal. Tese (Doutorado), 2018, 408f. 
Universidade Estadual Paulista. Faculdade de Arquitetura, Artes e Comunicação, Bauru, 2018.

DAVIS, Angela. Mulheres, raça e classe. Rio de Janeiro: Boitempo, 2016.

FOUCAULT, Michael. Microfísica do Poder. São Paulo: GRAAL, 2012

GOELLNER, Silvana. Mulher e esporte no Brasil: entre incentivos e interdições elas fazem história. Pensar a Prática (UFG), Goiânia, v. 8, n.1, p. 85-100, 2005.

HALL, Stuart. Da diáspora: Identidades e mediações culturais. Belo Horizonte: Editora UFMG, 2013.

HARAWAY, Donna. “Gênero" para um dicionário marxista: a política sexual de uma palavra. Cadernos Pagu, Campinas, n. 22, p. 201-246, jun. 2004. Disponível em: http://www.scielo.br/scielo.php?script=sci_arttext\&pid=S0104-

$83332004000100009 \& \operatorname{lng}=$ pt\&nrm=iso. Acesso em 5 mai. 2016.

JHALLY, Sut. The codes of gender: Media Education Foundation. Disponível em: www.mediaed.org/discussion-guides/The-Codes-of-Gender.pdf. Acesso em: 1 abr. 2020.

MEDITSCH, Eduardo. O jornalismo é uma forma de conhecimento? Media \& Jornalismo, n. 1, p. 9-22, 2002.

SCOTT, Joan Wallach. Gênero: uma categoria útil de análise histórica. Educação e Realidade, v. 20, n. 2, p. 71-79, 1995. Disponível em:

http://www.direito.mppr.mp.br/arquivos/File/SCOTTJoanGenero.pdf. Acesso em 9 out. 2016.

SILVA, Ana Célia da. A desconstrução da discriminação no livro didático. In: MUNANGA, Kabengele (Org.). Superando o racismo na escola. Ministério da Educação, Secretaria da Educação Continuada, Alfabetização e Diversidade. Brasília, DF: 2015.

VEIGA DA SILVA, Márcia. Saberes para a profissão, sujeitos possíveis: um olhar sobre a formação universitária dos jornalistas e as implicações dos regimes de podersaber nas possibilidades de encontro com a alteridade. Tese (Doutorado), 2015, $276 \mathrm{f}$. Programa de Pós-Graduação em Comunicação e Informação. Universidade Federal do Rio Grande do Sul, Porto Alegre, 2015.

VEIGA DA SILVA. Masculino: o gênero do jornalismo. Florianópolis: Ediufsc, 2014. UFSC, 2020, p. 22. 